Proceedings of the 11th Polish-Japanese Joint Seminar on Micro and Nano Analysis, Gniew, September 11-14, 2016

\title{
The Comparative Study of the Microstructure and Phase Composition of Nanoausferritic Ductile Iron Alloy Using SEM, TEM, Magnetometer, and X-Ray Diffraction Methods
}

\author{
E. SkOŁEK ${ }^{a *}$, T. GiętKA ${ }^{b}$, W.A. ŚwiĄTnicki ${ }^{a}$ AND D. MyszkA ${ }^{c}$ \\ ${ }^{a}$ Warsaw University of Technology, Faculty of Materials Science and Engineering, \\ Wołoska 141, 02-507, Warsaw, Poland \\ ${ }^{b}$ University of Science and Technology, Department of Materials Science and Engineering, \\ al. prof. S. Kaliskiego 7, 85-796 Bydgoszcz, Poland
}

${ }^{c}$ Warsaw University of Technology, Faculty of Production Engineering, L. Narbutta 85, 02-524 Warsaw, Poland

In this paper the microstructure and phase composition of ausferritic ductile iron alloy were investigated by scanning electron microscopy, transmission electron microscopy and X-ray diffraction methods. In order to obtain the nanoausferritic microstructure in the alloy, the austempering heat treatment was performed at relatively low temperature. As a result, a specific kind of microstructure, containing nanocrystalline ausferrite and retained austenite blocks, was obtained in each heat-treated sample. The volume fractions of phases were determined using different methods: MicroMeter software for scanning electron micrographs, stereological analysis for transmission electron micrographs, quantitative analysis of the X-ray diffraction spectra and magnetometer measurements. All methods revealed a high amount of retained austenite which varied as a function of the austempering treatment parameters. It was shown that the quantitative phase composition measured by X-ray diffraction and magnetometer, in all samples investigated, differs significantly from the stereological measurements and image analysis performed through the MicroMeter software. The possible reasons of the observed differences were discussed.

DOI: 10.12693/APhysPolA.131.1319

PACS/topics: 61.05.-a, 06.60.Mr, 81.05.Bx, 81.07.Bc, 81.40.-z, 81.40.Ef, 81.40.Gh

\section{Introduction}

An austempered ductile iron (ADI) is classified as a modern cast iron alloy, which is usually subjected to austempering heat treatment. This material is widely used for structural applications due to its good mechanical parameters that combine high strength and ductility. The high ductility of the ADI arise from the presence of retained austenite, whose content depends mainly on a kind of designed and performed heat treatment.

In recent years, a lot of investigations paid attention to modifications of heat treatments usually used for cast ductile iron alloys, in order to optimize their microstructure and phase composition [1-4]. One of directions of the research work was to produce the alloys with nanocrystalline microstructure and precisely designed phase composition [4-7]. However, to control the phase composition, especially the content of the retained austenite is not an easy task and needs application of the accurate methods of phases volume fraction determination.

Scientists working with ADI attempted to estimate the content of retained austenite on the basis of micrographs image analysis, and compared their results to measurements obtained by other methods, e.g. X-ray diffraction (XRD) [8-10] or magnetic measurements [8]. However, these results often differ from one another [8].

\footnotetext{
*corresponding author; e-mail: emilia.skolek@wimpw.edu.pl
}

The aim of the present study was to characterize the microstructure of austempered ductile iron at different scales of observations and to determine the phase composition of heat-treated samples using various methods. The proposed methodology can be also use to analyze the retained austenite content in nanocrystalline steels produced by phase transformations.

\section{Material}

Research has been conducted on a ductile cast iron, with a chemical composition presented in Table I, and different initial microstructure of the matrix: ferriticpearlitic in the case of ADI-1 and ausferritic in the case of ADI-2. The samples were subjected to different variants of heat treatment consisting of austenitization at $930{ }^{\circ} \mathrm{C}$ followed by austempering heat treatment at $300^{\circ} \mathrm{C}$. The parameters of the heat treatment were determined, through the examination of phase transformations, by means of dilatometric tests, on which basis time-temperature transformation (TTT) diagrams were created (Fig. 1). The time of isothermal hold was stated at the end of bainitic transformation.

TABLE I

Chemical composition [wt\%] of the ductile iron.

\begin{tabular}{c|c|c|c|c|c|c|c|c|c}
\hline \hline $\mathrm{C}$ & $\mathrm{Si}$ & $\mathrm{Mn}$ & $\mathrm{Mg}$ & $\mathrm{Mo}$ & $\mathrm{Cr}$ & $\mathrm{Cu}$ & $\mathrm{P}$ & $\mathrm{Se}$ & $\mathrm{Fe}$ \\
\hline 3.35 & 3.62 & 0.18 & 0.06 & 0.59 & 0.03 & 0.031 & 0.038 & 0.012 & bal.
\end{tabular}




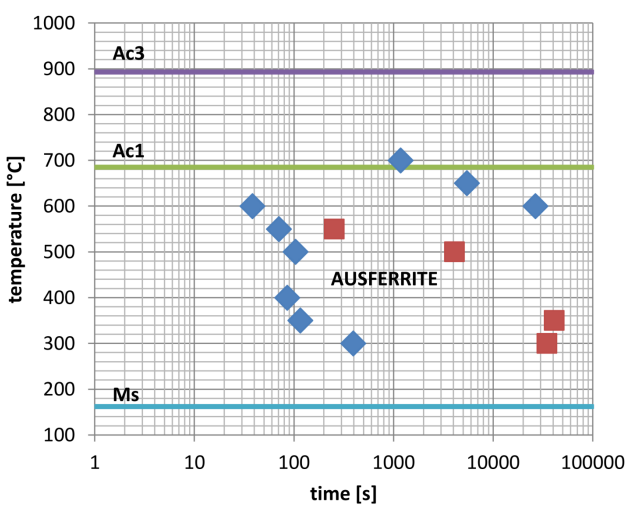

Fig. 1. Experimental time-temperature transformation (TTT) diagram for ADI investigated.

\section{Experimental}

All heat treated samples were subjected to the microscopic observation by use of a light microscope (LM), a scanning electron microscope (SEM) and a transmission electron microscope (TEM). For TEM investigation, the bright field (BF) and dark field (DF) observations were performed combined with electron diffraction pattern analyses. In order to quantitatively describe the microstructure (grain size, volume fraction of phases), the methods of stereological analysis were used. The TEM observations revealed that after austempering process the microstructure of the ADI matrix is composed of thin ferrite plates separated by thin layers of austenite. The thickness of the ferrite plates and of the austenite layers, was determined according to the following stereological formula [11]:

$$
d=2 L / \pi,
$$

where $d$ stands for the real size of the element of the microstructure (in the analysed case the real thickness of a plate) and $L$ is the size of the microstructure measured in the TEM image (in this case the width measured in the image). The plate widths $\left(L^{\prime}\right)$ were measured perpendicularly to the interphase boundaries. The content of each phase in the investigated microstructure was determined along the Cavalieri rule, according to which the volume fraction of a phase $V_{V}$ within the structure is equal to the area fraction in the image $A_{A}$, or to total length of line segments passing through a given phase with respect to the total length of the secants $L_{L}$ :

$$
V_{V}=A_{A}=L_{L} \text {. }
$$

The volume fraction of the retained austenite in the investigated microstructures was determined using a line method. In this method, the secants of the length $l$ are randomly placed on the TEM image. Each secant crosses the investigated phase $n$-times. The volume content $V_{V}$ of the investigated phase is the ratio of the sum of the widths $c_{i k}$ of the sections coming through (passing through) the investigated phase, divided by the total length $l$ of the secants

$$
V_{V}=\Sigma c_{i k} / l \text {. }
$$

Measurements of the volume fraction of retained auste- nite were performed against the matrix of ductile iron, excluding the volume fraction of spheroidal graphite. The amount of blocks of residual austenite was determined basing on the SEM observations under two magnifications: $\times 2500$ and $\times 5000$, using the MicroMeter software [12].

The total amount of residual austenite in the matrix of ductile iron, after various heat treatments, was also measured by means of XRD method with the use of cobalt radiation and iron filter.

Diffraction spectra were obtained in an angular range of $2 \Theta$ between $49.00^{\circ}$ and $63.00^{\circ}$, using a step of $0.02^{\circ}$. In this range, the diffraction lines of (110) $\alpha$ phase and (111) $\gamma$ phase were recorded. The phase identification was conducted by comparing the intensities arising from $d_{h k l}$ with the ASTM data. The volume fraction of austenite $(V \gamma)$ in the matrix of austempered ductile iron was determined from the formula $[1,2]$ :

$$
V_{\gamma}=\frac{1}{1+I_{\alpha} I_{\gamma}^{-1} R} \times 100 \%,
$$

where $V_{\gamma}$ - volume fraction of austenite, [\%]; $I_{\alpha}$ - total relative intensity of diffraction line of (110) $\alpha$ phase, planimetred on X-ray spectra; $I_{\gamma}$ - total relative intensity of diffraction line of (111) $\gamma$ phase, planimetred on $\mathrm{X}$-ray spectra; $R$ - constant adopted from [2]; for these measurements its value was 0.85 .

$$
V_{\gamma}+V_{\alpha}=100 \% \text {. }
$$

Magnetometric tests were performed using the vibrating sample magnetometer (VSM) in a magnetic field $2 \mathrm{~T}$ at room temperature.

\section{Results and discussion}

The LM observations revealed that as a result of austempering processes a typical microstructure containing lower ausferritic matrix with spheroidal graphite was produced (Figs. 2(left), 3(left)). Higher magnifications revealed a needle-shaped microstructure (Figs. 2(right, bottom), 3(right, bottom)). SEM observations at even larger magnification revealed needles of similar orientation, grouped in areas misoriented from one another (Figs. 2(bottom), 3(bottom)). Some small differences in the microstructure were observed between both alloys at that stage of observation. In the case of ADI-1 the microstructure seemed to be inhomogeneous and fragmented, packets and groups of needles were shorter and more misoriented from each other as compared to ADI-2. Those differences can be related to the initial microstructure of the matrix - ferritic-pearlitic in ADI-1 and ausferritic in ADI-2. In the light microscopy investigations, the small amount of non-etched, white areas, with characteristic regular shape and forming clusters were observed. This areas probably correspond to the retained austenite.

Observations performed by the TEM showed nanometric character of the microstructure (Figs. 4, 5). It means that each needle observed in LM and SEM image is composed of a package of nanometric layers parallel 


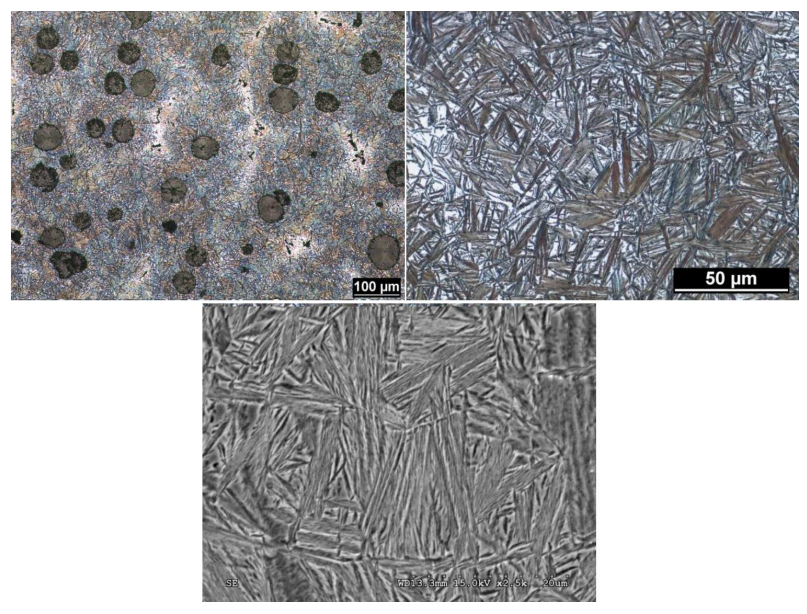

Fig. 2. Microstructure of ADI 1 revealed by LM (left, right) and by SEM (bottom).

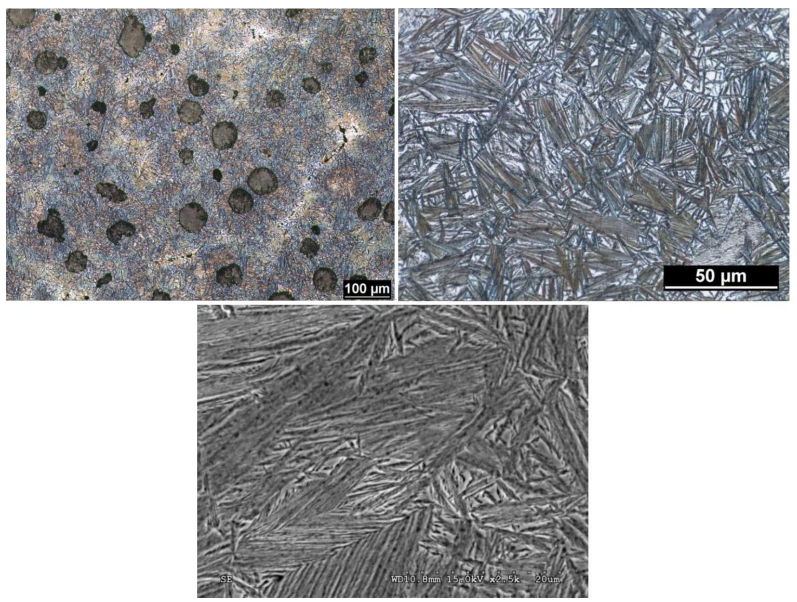

Fig. 3. Microstructure of ADI 2 revealed by LM (left, right) and by SEM (bottom).

to each other. Electron diffraction patterns analysis revealed that the microstructure consisted of thin bainitic ferrite plates separated by thin layers of retained austenite. In case of steels this kind of microstructure is called nanobainite [13-15], while in ductile iron we can speak of nanoausferrite $[6,7]$. The average width of ferritic plates was similar for both samples and it was $126 \pm 13 \mathrm{~nm}$ and $116 \pm 7 \mathrm{~nm}$ in ADI-1 and ADI-2, respectively. In the case of austenite layers some differences in average size were observed: $73 \pm 8 \mathrm{~nm}$ for ADI1 and $56 \pm 5 \mathrm{~nm}$ for ADI-2.

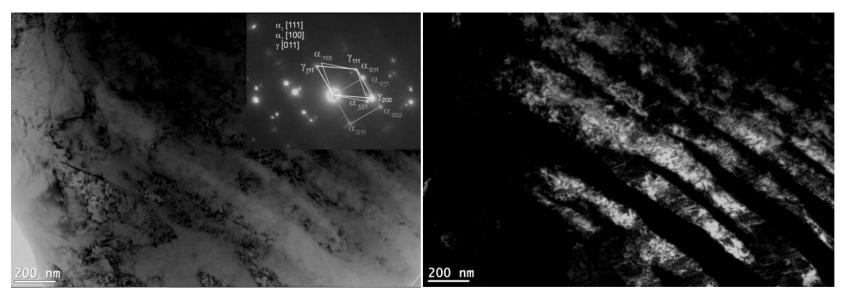

Fig. 4. Microstructure of ADI 1 (left), DF image (right) with the use of austenite reflection.

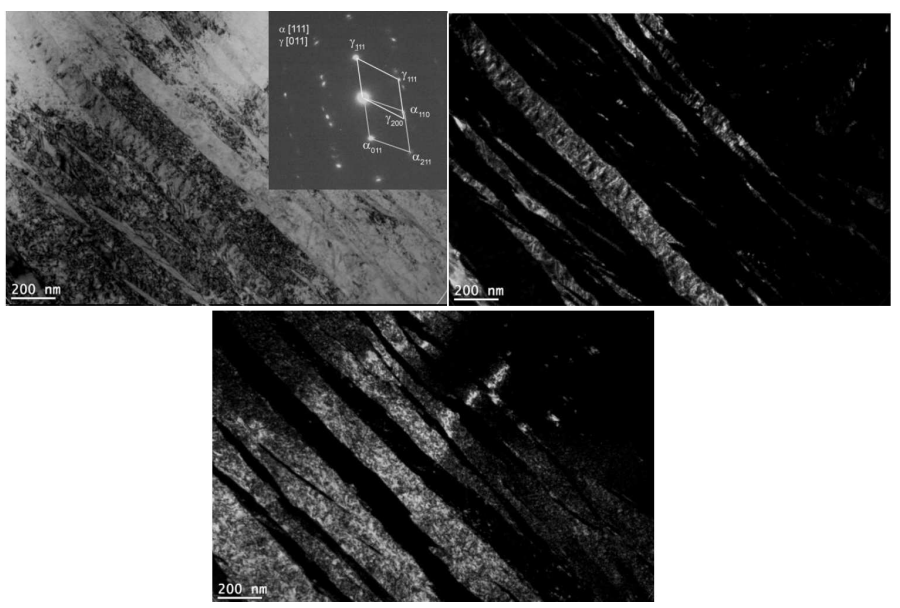

Fig. 5. Microstructure of ADI 2 (left), DF image with the use of austenite (right), ferrite (bottom).

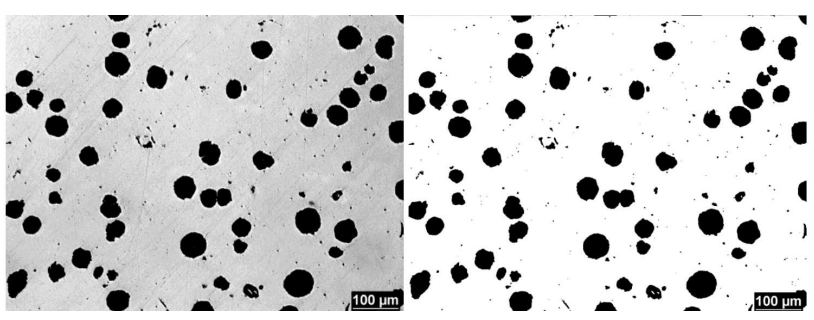

Fig. 6. Graphite particles in the matrix.

Since ADI contains spheroidal graphite, content, size and distribution of this phase should be known. It is important especially in terms of designing mechanical properties of ADI, but also for performing phase composition measurements. The amount of graphite can be estimated by image analysis with the use of MicroMeter software (Fig. 6). Calculated volume fraction of spheroidal graphite was similar for both samples and amounted to $12 \%$, and measurement error suggested uniform distribution of this phase in the matrix (Table II).

TABLE II

The volume fraction of graphite spheroidal graphite [\%] in ductile iron.

\begin{tabular}{c|c}
\hline \hline ADI 1 & ADI 2 \\
\hline $12.37 \pm 0.006$ & $12.14 \pm 0.007$
\end{tabular}

Other important parameters which determine ductility of the ADI are the volume fraction, size, and shape of the residual austenite in the ADI microstructure. Our previous study revealed that with increase of time and decrease of temperature of austempering, the ausferritic microstructure became more finer, and the amount and size of blocky austenite was reduced [16]. Thus, it can be assumed that after completion of bainitic transformation the amount of residual austenite should be very low. However, due to incomplete reaction phenomena a part of austenite usually remains untransformed in the microstructure [17].

Stereological analysis of TEM images revealed that the total amount of retained austenite was almost $42 \%$ for 
ADI-1 and $35 \%$ for ADI-2 which is relatively high. It can be related to the fact that in the TEM image only small, selected areas can be observed - usually areas consist of typically nanoausferritic microstructure, without blocks or thick layers of austenite are chosen. In addition, the size of TEM samples allows to analyse only a very small volume of material. Hence, it is difficult to properly analyse by means of this method, changes in phase composition and in microstructure that arise from large scale macrosegregation that usually occurs in cast ductile iron. Therefore, it can be assumed that amount of retained austenite estimated by means of this method refers to the content of this phase only in a typical nanoausferrite and it is weighted with significant measurement error.

TABLE III

The amount of $\gamma$ phases in the matrix of ductile iron after various austempering heat treatments.

\begin{tabular}{|c|c|c|c|c|c|c|}
\hline \multirow{3}{*}{ Sample } & \multicolumn{4}{|c|}{ Stereological measurements [\%] } & \multirow{3}{*}{$\begin{array}{c}\text { XRD } \\
\gamma_{t o t}\end{array}$} & \multirow{3}{*}{$\begin{array}{c}\text { Magn. } \\
\Delta_{r}^{*}\end{array}$} \\
\hline & \multicolumn{2}{|c|}{$\gamma_{\text {blocks }} \mathrm{SEM}$} & \multirow{2}{*}{$\begin{array}{c}\gamma_{\text {layers }} \\
\text { TEM }\end{array}$} & \multirow[t]{2}{*}{$\gamma_{t o t}$} & & \\
\hline & $\times 2500$ & $\times 5000$ & & & & \\
\hline ADI 1 & $12.5 \pm 4.9$ & $11.4 \pm 4.2$ & $41.9 \pm 4.4$ & 43.12 & 28.01 & .66 \\
\hline ADI 2 & $12.8 \pm 4.8$ & $14.4 \pm 5.8$ & $35.3 \pm 4.2$ & 38.49 & 29.69 & $25 \pm 1.66$ \\
\hline
\end{tabular}

*The volume fraction of retained austenite is a difference $\Delta_{r}=V_{V \text { para }}-V_{\text {Vgraphite }}[\%]$. The content of paramagnetic phase $V_{V \text { para }}$ is determined by magnetic measurements, the volume fraction of graphite $V_{V \text { graphite }}=12 \%$.

TABLE IV

Size of blocks $\left[\mu \mathrm{m}^{2}\right]$ of residual austenite, micrometer determinations.

\begin{tabular}{c|c|c|c|c}
\hline \hline \multirow{2}{*}{ SEM } & \multicolumn{2}{|c|}{ ADI 1 } & \multicolumn{2}{c}{ ADI 2 } \\
\cline { 2 - 5 } & min. & max. & min. & max. \\
\hline$\times 2500$ & 0.24 & 40.48 & 0.21 & 43.25 \\
$\times 5000$ & 0.23 & 17.24 & 0.28 & 28.33
\end{tabular}

On the other hand, the use of SEM at a low magnification enables performing investigation of more representative areas of the microstructure. Combining the SEM and MicroMeter software allows, at least in principle, to estimate the amount of retained austenite. However this method also presents some problems and limitations. First of all, at a lower magnifications it is very difficult to separate very small and thin microstructure elements (Fig. 7(left column)) and thus it is not possible to reveal the microstructure within the nanoausferritic areas. Another problem to be faced is that the contrast between the phases in SEM is generally very weak, grains are feathered or blurry, not to mention the software capacities that are too low to define interphase and grain boundaries. It follows that SEM permits to reveal the austenite only if this phase occurs in a form of relatively large grains and does not allow to perform a complete phase analysis. On the other hand, this method can be very useful to analyse the amount and size of blocks of residual austenite. However, due to differences in the contrast at the edges and inside of the blocks of residual austenite, a significant percentage of this phase can be missed (Fig. 7(left bottom)). Therefore it is necessary to outline the blocks of retained austenite before the MicroMeter analysis is performed (Fig. 7(right column)). The results of MicroMeter analysis of blocky austenite on the basis of SEM images at two magnifications are similar (Table III). Lower magnifications give better possibility to analyse the total amount as well as size of blocky austenite (Figs. 7, 8, Table III, IV). At higher magnifications, the observed areas are smaller and blocks can be partially missed, or, only austenite blocks are visible.

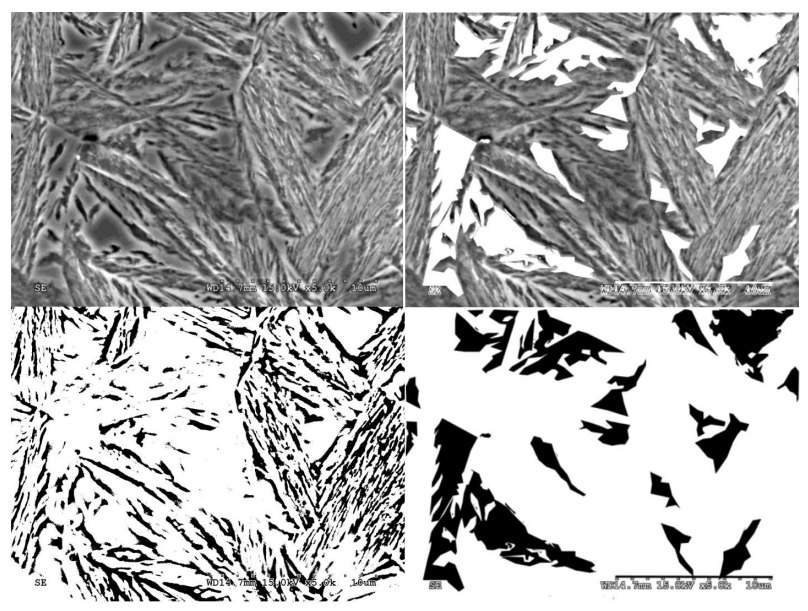

Fig. 7. The image analysis with the use of a graphic program and MicroMeter software: (left column) the analysis without previous image processing, (right column) the analysis after image processing.

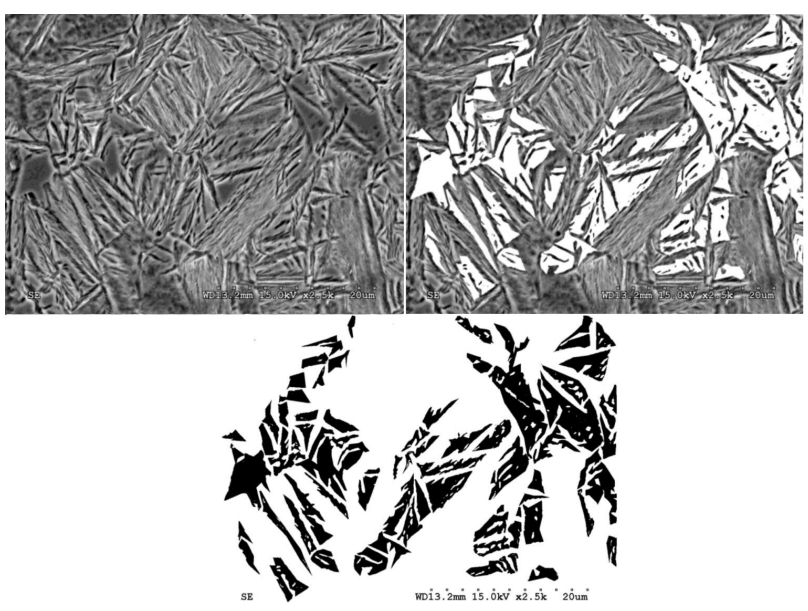

Fig. 8. The image analysis with the use of a graphic program and MicroMeter software.

On the basis of all stereological estimations the following formula was proposed to calculate the volume fraction of residual austenite:

$$
\begin{aligned}
& V_{V}(\gamma)_{\text {tot }}=\left(1-V_{\text {Vgraphite }}\right)\left\{V_{V}\left(\gamma_{\text {blocks }}\right)\right. \\
& \left.\quad+\left[V_{V} \text { (ausferrite }\right) V_{V}\left(\gamma_{\text {layers }}\right]\right\} .
\end{aligned}
$$

Table III shows the amount of residual austenite that was determined utilizing different methods. As seen in the table, there are significant differences in austenite content, 
depending on the method of investigation applied. The volume fraction of austenite determined by XRD is $28 \%$ and $29.7 \%$ for ADI- 1 and ADI-2, respectively. These values were higher than those determined by magnetic method. The highest values of residual austenite were obtained from the stereological calculations. That discrepancy might result from the ADI microstructure heterogeneities which occur because of the gradients of the chemical composition in the matrix between the graphite precipitates and interdendritic regions. The gradients in carbon content and in other alloying elements might strongly influence the phase composition in a given area. Thus the determined austenite content in smaller areas, as those registered in TEM micrographs, might not be representative of the overall microstructure of the investigated alloy.

Volumetric measurements by means of XRD or the magnetic method allow to analyse bigger volume of the material. In the case of magnetometer measurements, the obtained results do not directly indicate the phases but rather show their magnetic properties. By the use of the magnetic measurements about $64 \%$ and $63 \%$ of ferromagnetic phase which were obtained in ADI-1 and ADI-2 respectively, the remainder was the paramagnetic phase. Graphite is a paramagnetic phase, therefore to find the amount of retained austenite a $12 \%$ of graphite phase was subtracted from the total volume fraction of paramagnetic phase. In case of the XRD method, there are known problems with broadening and shifting diffraction peaks because of a nanostructure, an internal stresses occurring in the material, as well as due to supersaturation of phases with some chemical components. All of these factors appeared in investigated samples: nanostructure, stress as a result of heat treatment and bainitic transformations, as well as the supersaturation of austenite with carbon, which made it difficult to analyse the influence of the diffraction spectra. However, similar results of measurements of XRD and VPS suggest that the investigations were made properly.

\section{Conclusions}

1. The microscopic investigations at different stages of observation showed that as a result of austempering of ductile iron, the complex multi-phase microstructure was produced. It consisted of graphite particles embedded in the two-phase austeniticferritic matrix. The matrix was composed of a mixture of ausferritic regions and the blocks of untransformed austenite. The ausferritic regions were composed of ferritic plates alternating with layers of retained austenite.

2. The thickness of ferritic plates and austenitic layers was of the order of $100 \mathrm{~nm}$, which means that the ausferritic regions can be classified as a nanocrystalline constituent. That kind of microstructure was formed during prolonged austempering process which allowed the formation of high density bainitic ferrite plates, which, in turn, led to strong fragmentation of the austenite and to the reduction of the size of austenite blocks.

3. The total amount of austenite $V_{V}(\gamma)_{t o t}$ is the sum of the amount of austenite blocks $V_{V}\left(\gamma_{\text {blocks }}\right)$ and the amount of austenite in the form of thin layers occurring in the ausferrite and can be determined by Eq. (6).

4. SEM/MicroMeter analysis performed at required low magnifications allows to estimate the content of blocky austenite.

5. TEM analysis is superior to other methods as it concerns estimation of the austenite volume fraction contained in the nanoausferritic regions.

\section{Acknowledgments}

The results presented in this paper have been obtained within the project of the National Center for Research and Development "Development of innovative methods manufacture of gears having nanocrystalline structure based on foundry technology" (PBS3 nos. 246715, 2015-2018).

\section{References}

[1] A. Nofal, No. J. Metall. Eng. 2, 1 (2013).

[2] M. Soliman, A. Nofal, H. Palkowski, Mater. Des. 87, 450 (2015).

[3] S.K. Putatunda, G.A. Bingi, J. Mater. Sci. Eng. Adv. Technol. 5, 39 (2012).

[4] S. Panneerselvam, C.J. Martis, S.K. Putatunda, J.M. Boileau, Mater. Sci. Eng. A 626, 237 (2015).

[5] M. Hafiz, J. Al Azhar Univ. Eng. Sect. 5, 59 (2010).

[6] D. Myszka, E. Skołek, A. Wieczorek, Arch. Metall. Mater. 59, 1217 (2014).

[7] D. Myszka, K. Wasiluk, E. Skołek, W. Świątnicki, Mater. Sci. Technol. 31, 829 (2015).

[8] D. Myszka, T. Giętka, Arch. Foundry Eng. 11, 135 (2011).

[9] T. Giętka, S. Dymski, Arch. Foundry Eng. 10, 57 (2010).

[10] T. Giętka, S. Dymski, J. Polish CIMAC 5, 27 (2010).

[11] L.C. Chang, H.K.D.H. Bhadeshia, Mater. Sci. Technol. 11, 874 (1995).

[12] T. Wejrzanowski, L. Spychalski, K. Różniatowski, K.J. Kurzydłowski, Int. J. Appl. Math. Comput. Sci. 18, 33 (2008).

[13] H.K.D.H. Bhadeshia, Mater. Sci. Eng. A 481-482, 36 (2008).

[14] F.G. Caballero, M.K. Miller, C. Garcia-Mateo, C. Capdevila, S.S. Babu, Acta Mater. 56, 188 (2008).

[15] H. Beladi, Y. Adachi, I. Timokhinaa, P.D. Hodgson, Scr. Mater. 60, 455 (2009).

[16] XXI Physical Metallurgy and Materials Science Conf. AMT 2016, Rawa Mazowiecka 2016.

[17] F.G. Caballero, C. Garcia-Mateo, M.J. Santofimia, M.K. Miller, C. Garcia de Andres, Acta Mater. 57, 8 (2009). 